\title{
Surgical Management of Malignant Tumors of the Trachea: Report of Two Cases and Review of Literature
}

\author{
Ryuji Yasumatsu ${ }^{a}$ Junichi Fukushimac \\ Torahiko Nakashima $^{c}$ Hideki Kadota $^{c}$ Yuichi Segawa ${ }^{a}$ \\ Akihiro Tamae $^{a}$ Masato Kato ${ }^{b}$ Shizuo Komune ${ }^{c}$ \\ Departments of ${ }^{\mathrm{a}}$ Otorhinolaryngology and ${ }^{\mathrm{b}}$ Surgery, Hamanomachi Hospital, \\ and ${ }^{~}$ Department of Otorhinolaryngology, Graduate School of Medical \\ Sciences, Kyushu University, Fukuoka, Japan
}

\section{Key Words}

Tracheal cancer - Squamous cell carcinoma - Adenoid cystic carcinoma - Mediastinal tracheostomy

\begin{abstract}
Malignant neoplasms occurring from the trachea are extremely rare. Therefore, their clinical characteristics and surgical results have not been thoroughly discussed. These tumors are often misdiagnosed and treated as bronchial asthma or chronic obstructive pulmonary disease. It is critically important to probe the cause-effect relationship between the medical presentations and the clinical diagnosis. In this report, two cases of tracheal malignancy suffering from dyspnea due to obstruction of the proximal trachea are described, and a review of the literature is presented.
\end{abstract}

\section{Introduction}

Malignant neoplasms of the trachea are extremely rare. Grillo and Mathisen [1] reported that tracheal tumors account for only $2 \%$ of all lung tumors. Therefore, their clinical characteristics and surgical results have not been thoroughly discussed. In addition, there are extremely variable clinical and histological features [2, 3]. These tumors are often diagnosed late on account of delayed specific symptoms (blood sputum, coughing, dyspnea) [4-6]. The patients are often treated as bronchial asthma patients, and this misdiagnosis delays the proper treatment, leading to the inoperability of the tumor. 
The present study reports two cases of tracheal malignancy suffering from dyspnea due to obstruction of the airways and describes the clinical features of this rare disease.

\section{Case Reports}

\section{Case 1}

A 58-year-old man with a history of 40 cigarettes per day for 35 years presented to our hospital complaining of blood-streaked sputum and dyspnea. Two years before, he had suffered from laryngeal carcinoma and underwent radiotherapy (66 Gy) to the larynx in another hospital. A computed tomography (CT) and bronchoscopy documented a cauliflower-like, warty tumor ( $\underline{\text { fig. } 1 \mathrm{a}}$, b). The main tumors were located 25 and $50 \mathrm{~mm}$ below the vocal cords. Biopsy revealed squamous cell carcinoma (SCC). It was difficult to determine whether the tumor was a primary tracheal tumor or a recurrence of the previously treated laryngeal cancer. We started tracheostomy under local anesthesia to remove the tumors and secure his airways. After completing tracheostomy, radical surgery was carried out. The gross tumor extension did not exceed $5 \mathrm{~cm}$ up to the carina. However, the residual trachea was too short to perform a standard tracheostoma, and we decided to resect the manubrium, the clavicular head and the first costal cartilages to perform a mediastinal tracheostomy, as described by Grillo [7]. We performed the relocation of the trachea inferior to the innominate artery to avoid a potentially hazardous ligation of this vessel. The mediastinal stoma and upper mediastinal defect were covered by a pectoralis major myocutaneous flap, as described by Biller et al. in 1980 [8]. This confident flap provided well-vascularized muscle to fill the dead space in the upper mediastinum and created a bulky interposition between the trachea and innominate artery (fig. $2 \mathrm{a}$, b). The postoperative course was uneventful and the patient was discharged home on the 20th postoperative day. The patient had an excellent long term outcome, and there was no evidence of recurrence after 20 months of follow-up.

Case 2

A 58-year-old woman presented with cough and breathlessness of 2 weeks duration. She denied a history of chest pain, hemoptysis, dysphagia and hoarsness of voice. Local examination of her neck revealed a $4 \times 3 \mathrm{~cm}$ firm, nontender swelling fixed to the underlying structures. Other systemic examination was unremarkable. The patient was referred for fine needle aspiration cytology. Cytological findings revealed adenoid cystic carcinoma (ACC). Fiberoptic bronchoscopy was performed which showed a well-defined, solitary, smooth-surfaced mass at the anterior wall of the trachea. A CT showed a voluminous, wall-thickening, and solid tracheal mass of about 3-4 cm in length, extending from the subglottic space to the cervical trachea (fig. $3 \mathrm{a}, \mathrm{b}$ ). We performed a tracheostomy under local anesthesia to secure her airways. After completing tracheostomy, an open biopsy was performed and histological findings revealed ACC. The patient underwent pharyngolaryngectomy, right neck dissection, and microvascular free jejunal transfer (fig. $4 \mathrm{a}, \mathrm{b}$ ). No perioperative and postoperative complications occurred and there was no evidence of recurrence after 18 months of follow-up.

\section{Discussion}

Tracheal tumors are rare and account for only $2 \%$ of all respiratory tract tumors. A variety of histological features of tracheal tumors have been reported, including benign, low-grade, and high-grade malignancies [4, 9].

SCC is the most common tracheobronchial malignancy and develops mainly in the 6th and 7th decades of life. This tumor is strongly associated with habitual cigarette smoking, affecting men two to four times more frequently than women $[9,10]$. Approximately $40 \%$ of all tracheobronchial SCCs have been reported to occur before, concurrently with, or after carcinoma of the oropharynx, larynx, or lung. Our first case had a history of radiotherapy for laryngeal cancer. 
ACC is the second most common tracheal malignancy determined at histology after SCC $[10,11]$. ACC tends to occur in the central airways such as the trachea, main bronchus, or lobar bronchus; a peripheral or segmental location is uncommon. These tumors are generally thought to have low-grade malignant potential; however, they have a tendency for local recurrence and late development of distant metastasis. Because of their slow progression, these tumors cannot give any symptoms until airway obstruction occurs.

Common symptoms of tracheal malignancies include breathlessness, cough, hemoptysis, dysphagia, and stridor. However, these tumors are sometimes misdiagnosed because the symptoms can mimic those of asthma or chronic obstructive pulmonary disease $[3,12]$. Our ACC case was also treated first as an asthma patient for 2 months.

Rapid evaluation of the tumor (severity of tracheal stenosis, location, length, and invasion status) and the possibility for surgical resection is the most important strategy for patients with stenosis of the central airways due to tracheal tumors. CT is a useful imaging procedure for tracheal tumors [13]. The conventional CT scan of the chest and trachea is recommended for this kind of tumor, and endoscopic examination is the best way to evaluate obstruction.

A complete resection, if possible, provides the best potential benefit as well as symptomatic relief for patients with primary tracheal tumors such as SCC and ACC [14, 15]. However, because tumors with malignant potential tend to infiltrate along the airways, they are often incompletely resected and thus prone to recur locally. The complete resection rates in reported cases range from 42 to $57 \%$. In our cases, we could treat the patients surgically by the total removal of the larynx and its reconstruction, performing mediastinal tracheostomy (first case) or pharyngolaryngectomy (second case). External beam irradiation has commonly been used for palliative treatment of tracheal cancer and its palliative potential is reasonable [16]. Several studies have demonstrated the value of radiotherapy in controlling primary tumors of the trachea, providing good palliation in $75 \%$ of the patients and a 5 year survival rate of up to $10 \%[17,18]$.

Prognosis of patients with tumors of the trachea remains poor. Extensive resection provides disease control and allows to obtain 5-year survivals for $20-40 \%$ of the SCC patients and $60-100 \%$ of the ACC cases $[1,19]$.

In conclusion, we reported two cases of tracheal cancer with stenosis of the proximal trachea. It is critically important to probe the cause-effect relationship between the medical presentations and the clinical diagnosis. Failure to respond to general therapy suggests that the primary diagnosis should be suspected. A smoker presenting dyspnea could be carrier of a tracheal neoplasm, and early diagnosis is very important for its management. 

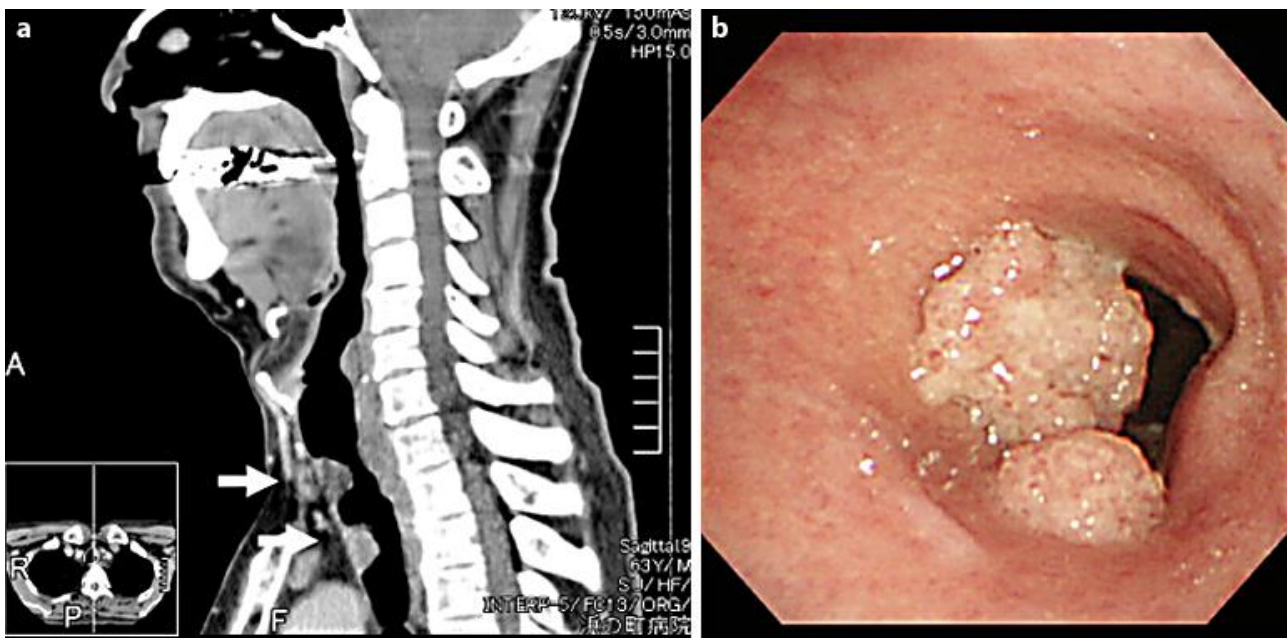

Fig. 1. a Tumors are located 25 and $50 \mathrm{~mm}$ below the vocal cord (arrows). b Bronchoscopic examination reveals papillomatous tumors under the subglottis.

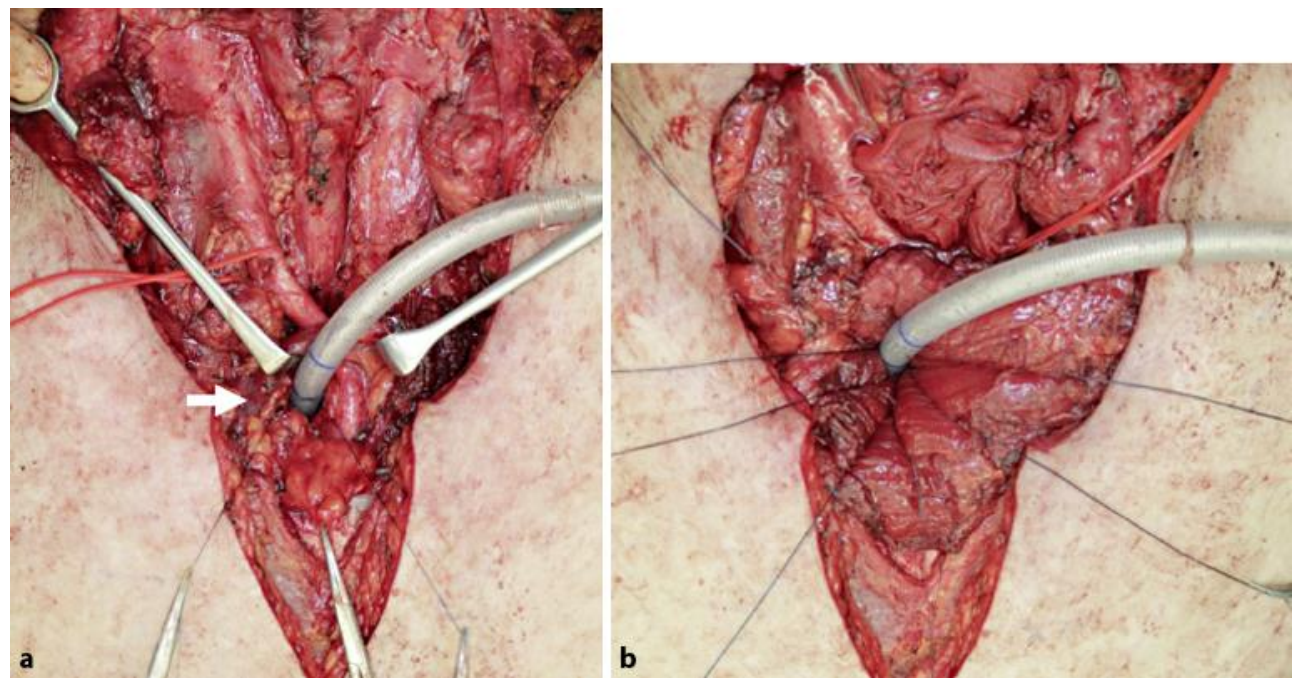

Fig. 2. a Operation view of the tracheal stump after its relocation inferior to the innominate artery (arrow). b Reconstruction of the cervical and upper mediastinal defects using a pectoralis major myocutaneous flap. 

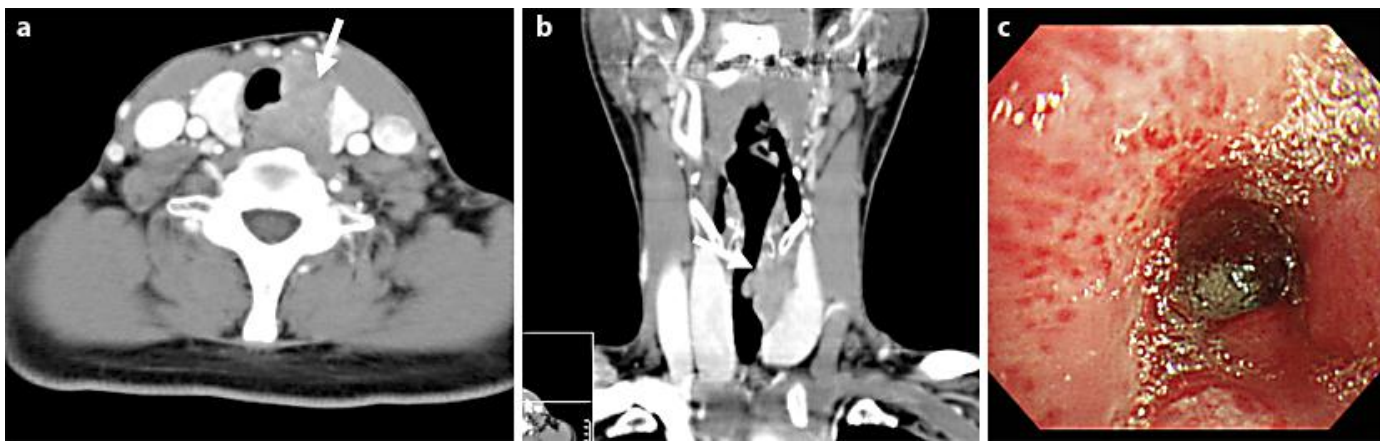

Fig. 3. a The tumor is located in the posterolateral wall of the trachea (arrow). b Coronal view. The arrow indicates the tumor. $\mathrm{c}$ Bronchoscopic examination reveals a smooth mass under the subglottis, with obstruction of the lumen.

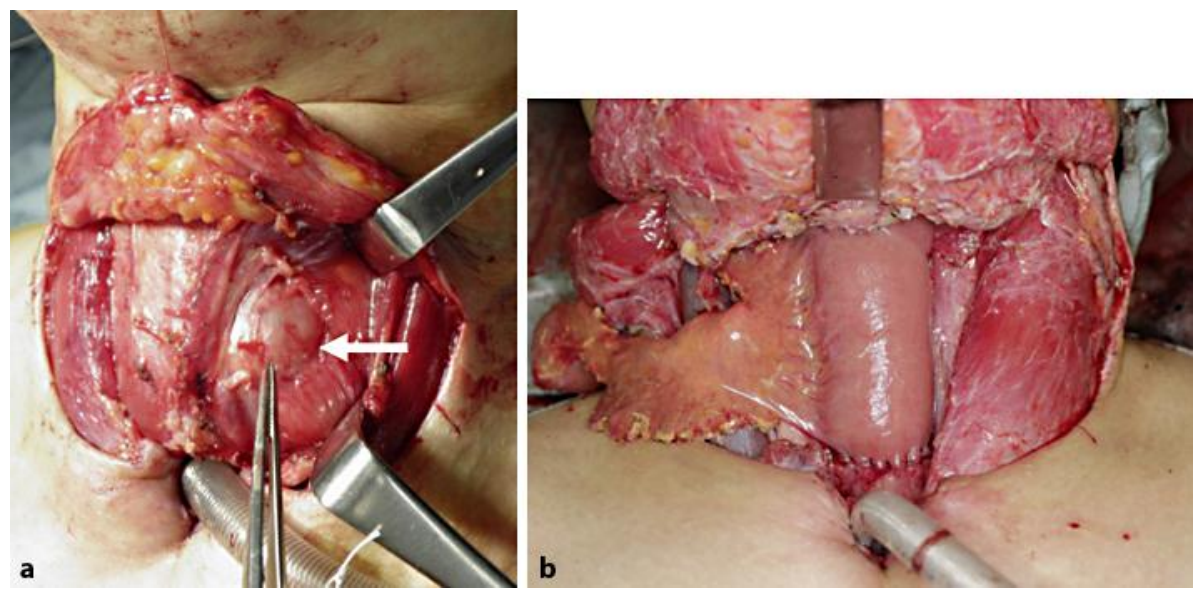

Fig. 4. a Operation view of the cervical tumor (ACC) before the open biopsy (arrow) was performed. b Reconstruction of the hypopharynx and cervical esophagus using free jejunal transfer.

\section{References}

1 Grillo HC, Mathisen DJ: Primary tracheal tumors: treatment and results. Ann Thorac Surg 1990;49:69_ 77.

2 Aberle DR, Brown K, Young DA, Batra P, Steckel RJ: Imaging techniques in the evaluation of tracheobronchial neoplasms. Chest 1991;99:211-215.

-3 Schneider P, Schirren J, Muley T, Vogt-Moykopf I: Primary tracheal tumors: experience with 14 resected patients. Eur J Cardiothorac Surg 2001;20:12-18.

4 Webb BD, Walsh GL, Roberts DB, Sturgis EM: Primary tracheal malignant neoplasms: the University of Texas MD Anderson Cancer Center experience. J Am Coll Surg 2006;202:237-246.

5 Howard DH: The miracle at the Radcliffe Infirmary. How a son of Adelaide and a mould changed the world. J Med Vet Mycol 1994;32(suppl 1):9-16.

-6 Li W, Ellerbroek NA, Libshitz HI: Primary malignant tumors of the trachea. A radiologic and clinical study. Cancer 1990;66:894-899.

7 Grillo HC: Tracheal tumors: Surgical management. Ann Thorac Surg 1978;26:112-125.

-8 Biller HF, Krespi YP, Lawson W, Baek SM: A one-stage flap reconstruction following resection for stomal recurrence. Otolaryngol Head Neck Surg 1980;88:357-360. 
-9 Macchiarini P: Primary tracheal tumours. Lancet Oncol 2006;7:83-91.

10 Gaissert HA, Grillo HC, Shadmehr MB, Wright CD, Gokhale M, Wain JC, Mathisen DJ: Uncommon primary tracheal tumors. Ann Thorac Surg 2006;82:268-272; discussion 272-273.

11 Allen MS: Malignant tracheal tumors. Mayo Clin Proc 1993;68:680-684.

12 Refaely Y, Weissberg D: Surgical management of tracheal tumors. Ann Thorac Surg 1997;64:1429-1432; discussion 1432-1433.

13 Nuwal P, Dixit R, Singhal AK: Primary adenoid cystic carcinoma of trachea presenting as midline neck swelling and mimicking thyroid tumor: a case report and review of literature. Lung India 2010;27:167169.

14 Abike F, Bingol B, Temizkan O, Dunder I, Kilic GS, Cetin G, Gundogdu C: Primary tracheal adenocystic carcinoma and tracheal tumors during pregnancy. Rare Tumors 2011;3:e33.

15 Wood DE: Management of malignant tracheobronchial obstruction. Surg Clin North Am 2002;82:621642.

16 Makarewicz R, Mross M: Radiation therapy alone in the treatment of tumours of the trachea. Lung Cancer 1998;20:169-174.

17 Jeremic B, Shibamoto Y, Acimovic L, Milisavljevic S: Radiotherapy for primary squamous cell carcinoma of the trachea. Radiother Oncol 1996;41:135-138.

18 Manninen MP, Pukander JS, Flander MK, Laippala PJ, Huhtala HS, Karma PH: Treatment of primary tracheal carcinoma in Finland in 1967-1985. Acta Oncol 1993;32:277-282.

19 Maziak DE, Todd TR, Keshavjee SH, Winton TL, Van Nostrand P, Pearson FG: Adenoid cystic carcinoma of the airway: thirty-two-year experience. J Thorac Cardiovasc Surg 1996;112:1522-1531; discussion 1531-1532. 